\title{
The eye of the beholder - utility and beauty in mine closure
}

\author{
BE Harvey The University of Queensland, Australia
}

\begin{abstract}
Maximising sustainable mine closure outcomes requires a business-connected approach that takes full advantage of ongoing human and economic occupation of former mine sites. This is evidenced in the majority of successful mine closures around the world, particularly in well-populated regions. Flying in the face of this experience, current mine closure regulation, planning and implementation frequently focuses on the minutiae of environmental remediation. These two perspectives are laced with inherent tensions and contradictions that, left unresolved, will lead to suboptimal mine closure plans that will be difficult to reset when new ideas and economic options emerge. Companies, communities and regulators faced with mine closure scenarios should explicitly place future economic occupation of mine sites at the forefront of mine closure visioning and leave open future options for creative human enterprise.
\end{abstract}

\section{The big picture}

Major market-traded companies in the extractive sector have commendably embraced social responsibility. Unfortunately, under the influence of global commentators, this extends to indeterminate ideas like environmental net positive impact and the precautionary principle. This is understandable; greenfield extractive projects, particularly mining, are frequently located in economic frontiers and in environmental landscapes deemed pristine. Urban commentators with secure first-world livelihoods imbue such places with something resembling spiritual sanctity and believe there can never be enough of it.

Compounding this, the apocalyptic tradition that manifests in every generation of humanity seeks to find cause and effect in big ideas, such as the global biodiversity crisis, nuclear holocaust, global climate change, and ocean acidification. This type of global thinking is often referred to as the big picture and inevitably weaves itself into closure planning. Conversely, people living in economic frontiers have concerns that are much more prosaic and local. They want more reliable food supplies with higher protein, they want access to dependable health services, they want their cultural values protected and they want economic opportunity, particularly for their young people. This incongruence is revealed in emerging papers on social mine closure planning, for instance by Adey and Whitbread-Abrutat (2013).

Some concepts, such as ecosystem services theory, known in traditional societies as the interconnectedness of things, attempt to reconcile global with local knowledge, but mostly the concerns and knowledge of local people, born of many generations of hard won experience, are sidelined by global commentators.

Inevitably the big picture prevails and influences governments and public policy. A growing number of regulatory requirements, generated without reference to local knowledge and experience, describe how the extractive sector should contribute to society by improving the natural environment. Companies and institutions like the International Council on Mining and Metals have responded with an impressive array of tools for planning, analysing and measuring environmental effects and closure prognosis that reflect general principles and instrument precision more than context-specific material hazard or opportunity (Thomson 2013; ICMM 2011).

Despite good intentions, the big picture approach is fundamentally flawed. Much of the activity and behaviour it generates is not connected to the core business of extractive companies nor local community aspirations and capabilities. It does not gain traction because it fails to attract the support of those people whose comprehension is most vital: local people and mine site managers. Big picture thinking is replete 
with good intentions but it can lead to unintended consequences; it fails to properly engage with host communities on reciprocal terms; it encourages companies to adopt priorities and behaviours which can blur appropriate boundaries between firms, governments and communities; and, ironically, it will frequently result in sub-optimal local environmental and economic outcomes.

Reflecting specifically on mine closure options, there appears to be a view in highly urbanised and otherwise sparsely populated places like Australia that mine closure should involve returning land to some approximation of a pristine environment. This prevailing view is readily apparent in the weighting of papers on mine closure that are directed to exclusively environmental considerations in one form or another, whereas there is much less being written about economic options for mine closure. In fairness, rather than reflecting any deliberate marginalisation, this is probably the result of the maturity enjoyed by the environmental profession within the extractive sector and the relative immaturity of the still emerging professional discipline of social performance.

The result is one of manifest research and public policy distraction away from the very dimension that has demonstrated the greatest success in mine closure; mine site regeneration as an ongoing economic asset.

\section{Social performance}

The term social performance is appearing more frequently in company publications and resource sector literature, against a backdrop of terminology over the past two decades that has served to confuse more than clarify. Terms such as corporate social responsibility, social sustainability, social license and community relations might evoke high-minded intent at corporate headquarters, but singularly fail to arouse understanding and accountable action by managers and employees at operating assets.

In this context, job-site operators understandably believe that working with host communities is not part of their personal work domain. This, and the labelling applied to it, leads to offset and mollification approaches under the exceptional, and often marginalised, accountability of specialists.

Vastly better options for mine impact mitigation and opportunity to secure community support for extractive operations come with organisational behavioural change and mobilising core competencies across the whole mining workforce. By calling this social performance, it signals very clearly to operators that their accountable attention to whole-of-site performance is required. It seeks to emulate the same degree of attention that industry over the past 20 years has afforded to safety performance and environmental performance, with spectacular success (Harvey 2013).

Complementing this whole-of-site accountability, extractive companies should unashamedly make clear that their motive for local engagement activities is self-interest, not altruism. If transparent self-interest is not at the core of public engagement, proposals will simply not be believed and mistrust will prevail.

The primary motive should be very clear to all: extractive companies want societal stability and what has become known as social license. This can be thought of in general terms as the broad-based positive sentiment of a self-assured host population towards the ongoing presence of a particular business and the legacy it will leave. When extractive company spokespersons claim their companies are altruistically seeking to improve social and environmental conditions, they fail the test.

Mining development in economic frontiers, like any point source wealth generator, frequently results in accelerated organic population growth rates and in-migration. In this context, a rapidly diversifying and growing local population challenges existing authority structures and traditional resource bases. Large numbers of disenfranchised and unemployed young people unable to satisfy economic and social aspirations can rapidly lead to law and order problems and societal breakdown. Miners in regions where the economic contrast is less stark face less intense versions of this syndrome.

In this predicable scenario, mining companies that foster expanding local economic options face a greatly reduced possibility of societal instability. Beyond mere mitigation, broadening the base of local enterprise from which a competitive business ecosystem can grow will service the mine as well as local residents and 
an economy beyond mine closure. Shifting the interaction focus from offset, compensation and charitable sponsorship, to one of active economic participation and growth in human capital serves to benefit all parties with a direct stake in a mining and processing operation.

Conversely, under offset and net positive impact approaches, external engagement is typically disconnected from the business and is farmed out to quarantined departments or supply side agents; and the fundamental behaviour of extractive sector operators frequently remains unchanged. To local people the companies continue to be seen as insular and uncaring. In fact, all the operational, safety, security and other systems at an extractive operation are perfect for maintaining quarantine and these tend to become inadvertently reinforced over time.

Encouragingly, under the incentives of the Equator Bank financing requirements and enlightened self-interest, a business- and community-centric approach is slowly emerging, one that involves behavioural competencies and the increasingly common professional discipline of social performance. The approach leverages off the competitive advantage of extractive companies themselves and does not seek to garner forgiveness through the sponsoring of offset programmes. For instance, properly constituted social impact and risk assessments make for in-depth comprehension of local issues associated with resource development. Based on this, professional approaches to enhancing beneficial contributions through core business activities are identified; and approaches for mitigating negative community impacts arising from things such as resettlement, in-migration and resource curse are well understood. There is, in fact, a developing curriculum that puts the social performance approach on the same footing as any of the other professional disciplines in the extractive sector.

Improving social performance requires changes in core business behaviours. An activity that contributes greatly to behaviour change is employee participation in properly constituted local induction courses, comparable to behavioural safety training. To be effective, such courses need to be crafted and facilitated by professional educators with the active involvement of local people. They should be tailored to local circumstance, not framed in universalisms and distant theory. Based on a desire to instil comprehension, not just compliance, local induction should provide historical and contemporary context and a secure social environment for employees and community members to discuss difficult issues.

Amongst other things, what employees learn in discussion with locals is how to properly behave in the local context, beyond superficial etiquette. This includes all employees, not just those deemed to be expatriate or dominant other. National staff members need the instruction as much as expatriates, particularly if they come from an urban parvenu background, which is where many young professionals in the extractive industry are recruited. While some of the learning may be about local customary norms, much of it will be about simply behaving with respect, such as: driving slowly and carefully past dwellings; not driving off-road across pasture land; not venturing into designated areas without agreement; how to mentor and if necessary discipline a local employee without causing shame; involving local perspectives on land-use planning, and who to contact to help resolve the inevitable community complaints and disputes that arise. Most importantly, the curriculum for local induction courses should reflect what is important to local people, and not be based on international agendas.

The next tier of activities should be addressed along departmental lines and formalised into commitments:

- Human Resources undertake concerted activities that address all the necessary steps to employ 'local-local' people, who have frequently never worked in an industrial environment, interlinked back into local educational options.

- Local-local refers to people with land and historical connections to the area directly affected by the mining activities, not people recruited from the national population who are frequently defined as local to meet regulatory targets and, contrary to wishful thinking, frequently exacerbate company-community tensions. 
- Procurement activities provide for scaffolding local-local service and supply on an escalating trajectory. Timely payment to fledgling local service providers with cash flow constraints is particularly important.

- Security activities acknowledge and provide for site security and access protocols involving local-local people who can serve as the ears and eyes, and who gain requisite recognition for their local status as custodians of civic order.

- Environmental activities acknowledge and involve local-local people in the understanding and management of environmental mitigation, intervention and monitoring - affording recognition of their status as custodians and their knowledge of the local landscape (Smith \& Thompson 2013).

- Finance and accounting participate in local-local governance and administrative issues, such as helping local-local government by providing advice on fiscal management and audit, and assistance with submissions to central government.

- Infrastructure and asset management design and manage company assets and ancillary infrastructure in a way that provides for maximum civic access.

- Maintenance and operations recognise and actively buy-in to mentoring young local-local people as trainees and fostering their development as future valuable artisans and employees.

- Occupational Health and Safety recognise and enhance the natural tendency for employees to take learnt safety behaviours home, such as wearing of seat belts, drug and alcohol self-management and measures to reduce communicable disease.

- Management consciously recognises that securing social, and particularly local-local, support for a business is a fundamental responsibility for general management. Managers need to spend a serious amount of time securing and maintaining social license. Farmers, mayors and tribal leaders are effectively the CEOs of their institutions; they want to be treated accordingly and discuss important issues with their business peers.

Bringing social performance into the heart of the business under the accountability of day-to-day line managers is the key to success. Industry has not farmed out safety accountability. Success has come from eliminating safety departments per se and making safety an explicit, hour-by-hour accountability of operational managers. Similarly, securing a social license, which by many accounts is the greatest risk the extractive sector faces, needs more embedded management of the safety accountability kind.

\section{Applying social performance to closure}

While social performance approaches are starting to be applied to the business of operational closure, for instance by actively engaging local land-connected people in landform design (Breadmore \& Lafferty 2015) or seeking to mitigate local socioeconomic impacts of mine closure (Costa 2015), these efforts are usually directed to supporting pre-determined uses for former mine sites. Conversely, when a high degree of open dialogue with local people is contemplated, it can result in irresolvable epistemological discord that makes closure consensus even more distant (Van Vlaenderen et al. 2013).

Instead of co-opting social performance to utopian approaches to mine closure planning, regulators and extractive companies would be well advised to work with entrepreneurs on closure options using open-minded, enterprise thinking. Such an approach acknowledges how little we know, it allows for step-by-step experimentation and the emergence of options that technological, economic and human innovation inevitably produces. It is true science, based on small scale, bounded-experimentation, always on the lookout for unintended consequences.

Enterprise tinkering does not agree with the political sentiment of big picture thinkers who favour regulatory rather than private approaches to planning and closure considerations. Private approaches take into account what local people and businesses might want, and what they are prepared to invent and adapt 
to. In contrast, holists believe that complete reconstruction is necessary and decide from the outset what the result will be, fundamentally violating the principles of the scientific method. Government officers, management consultants and environmental agencies are naturally attracted to the idea of a holistic outcome, probably because they believe that they will be in charge of it. They lose sight of the tendency for day-to-day problem-solving to be based on social discourse, where agreement is sought in the minutiae of compromise. Real problem-solving avoids committing to irreversible plans and regards all arrangements as adjustable.

In keeping with the principle of experimental tinkering, and contrary to the holistic approaches being promulgated through regulation in contemporary closure planning, actual on-ground mine closure success around the world usually involves multiple working hypotheses and the human and economic occupation of former mine sites. This makes good sense; post-mining landforms and infrastructure viewed as a form of built capital have ongoing value. While it is incumbent on the owner of the asset to ensure it is safe and free of potential hazards and toxins, what will most determine long-term success is a post-closure use that subsequent users really want and will take ownership of. The concept is better referred to as regeneration rather than the nihilism of remediation, and is ably explored by Jones and MacLean (2013) who describe the challenge of establishing a post-mining landscape to meet multiple ends in the Fort McKay region of Alberta, Canada.

A scan of the book "101 things to do with a hole in the ground" (Pearman 2009), produced by the Eden Project, indicates that all of the closure examples cited involve the ongoing human and economic occupation of former mine sites, including uses directed to environmental recreation. The range includes hydro storage facilities, outdoor concert venues, waste management, industrial estates, reconstituted farm lands and vine yards, forestry parks and trout lakes. The point is that successful closure scenarios, even those based on environmental values, invariably involve a continuing human presence with economic returns.

An equally important point is that this continuing human presence provides the best motivation for, and monitoring of, post-closure site integrity. When something has ongoing value and involves constant use, hence detailed scrutiny, dangerous deterioration is rarely going to occur. My challenge to closure planners is to not automatically elevate the holistic environmental rehabilitation option to first choice, but to promote tinkering, otherwise known as adaptive management, with economic options as first choice. In recommending this it has to be acknowledged that the biggest challenge will be to get political leaders and regulators to accept this, particularly in the light of long-ago formulated closure commitments based on the impossible vision of total environmental rehabilitation.

\section{$4 \quad$ Exemplifying case studies}

Several case studies serve to illustrate what is possible.

\subsection{Woodlawn}

In Australia, the Woodlawn poly-metallic mine, $250 \mathrm{~km}$ south of Sydney in New South Wales, ceased mining in 1998 after 20 years of openpit and underground operation. The lease area is now the site of several experimental enterprises, including the ongoing exploration of additional underground potential and the re-processing of tailings with improved technology. Of greater long-term consequence is the multi-purpose use of the former mine site for a range of purposes based on urban waste management.

Woodlawn now plays an important role in the long-term management of Sydney's waste under the innovative management of Veolia Environmental Services who acquired the site in 2004. The site currently takes 20 per cent of Sydney's organic waste, brought to the location by trains from transfer terminals following source separation through kerbside recycling innovation (Veolia 2014).

The waste fuels a bioreactor in the former Woodlawn open pit, generating enough power to supply over 2,500 households. Further processing includes the production of compost for agricultural sales and waste heat to support fish farming. Veolia has taken on the rehabilitation of the mine site and is developing a 
mechanical biological treatment facility for separating organics from mixed household waste to create compost to assist mine landscape regeneration and reduce the amount of waste going into landfill. Complementary activity includes a working farm and a $50 \mathrm{MW}$ wind farm exploiting landform and significant year-round winds.

Starting small, Veolia has employed experimental tinkering to work out what works, essentially by eliminating what does not, and was granted approval in 2012 to increase the annual waste input from 500,000 tonnes per annum to 1.13 million tonnes. At full capacity, the facility, including the bioreactor and the wind farm, is expected to generate $300,000 \mathrm{MWh}$ of power each year, enough to maintain the equivalent of 37,500 households. All the while paying for the incremental rehabilitation of the rest of mine site, contributing to the maintenance of local transport infrastructure and placing AUD 5 million over the past 10 years into a local community trust fund.

\subsection{Mireco}

Mining might be old history in Korea, but former mine sites live on through the innovative regeneration options explored and encouraged by Mireco, now an international services company. Established in 2005 as a state-run entity to fix up the damage of mine sites from a foregone era, Mireco estimates that its domestic mine rehabilitation industry now generates over USD 80 million a year (Mireco 2013).

Hi-tech innovations developed in present day Korea, such as waste water purification with bacteria, the removal of heavy metals from mine waste and optical sensing of land subsidence, have progressively removed the damage of mining from Korea's pre-tech era and made them available for redevelopment. A particularly impressive example is the Kangwon Land tourist resort that includes high-rise residential apartments, a golf course, a casino, a multisport complex and a ski field, generating substantial revenue and local employment (Kangwon Land Co. Ltd. 2015).

Mireco is not a business conglomerate and it does not undertake the redevelopment work itself, rather it acts as a broker and facilitator for small, medium and large sized businesses to participate in government-sanctioned large-scale developments. Having run out of former mine sites in Korea, since 2010 Mireco has turned its attention to overseas markets and has undertaken business in 25 countries including Chile, Malaysia and Vietnam. Earnings to date are small, however Mireco estimates that the global mine regeneration market could be worth USD 7.6 billion, growing at six per cent per year.

The critical threshold crossed in both of the examples described is the realisation that mine site rehabilitation is not necessarily a liability. Viewed in the right way and brokered into second and third derivative businesses, economic options emerge. Tellingly, the primary miners and government regulators are not able to identify any of these options, because such ideas and experiments are simply beyond their competency and conservative mindsets.

\section{Conclusion}

In conclusion, while acknowledging that extractive operations should seek to preserve environmental capital to the extent that local people want it, mine closure approaches that seek to maximise the conversion of in situ mineral endowment into an expansion of human, social and built capital will have the greatest chance of success. Mining companies should not act singularly nor get distracted by global big ideas when selecting their closure vision; they should work closely with local people and other industry sectors to mobilise the inventiveness of capital markets and the experimental method in developing regeneration options. Hence social performance should not be formulaically applied to pre-determined holistic solutions, noting that in some circumstances seeking upfront communal consensus on post-closure land use will lead to confusion and conflict.

This is antithetical to the final-state mine closure plans now being required during permitting. For mines with projected mine life extending beyond a generation, such plans will inevitably be found wanting. While many people might regard them as interim holding devices (which is undoubtedly how most mine managers, 
regulators and political leaders, who will not be around to oversee deployment, will regard them), history tells us that wholesale regulatory adjustment that can cater for technical, economic and governance innovation will be very difficult. Hence, regulatory oversight of mine closure should not extend to detailed plans; rather it should be restricted to reviewable and inclusive vision setting and the establishment of endowments that are adaptable to new circumstance and local acceptance at the time of operational closure. Miners and regulators do not have the right mindsets and competencies to do this and with the large backlog of mines and legacy sites that will require attention over the next 20 years, a specialised secondary market approach is required.

In short, mine site regeneration based on a vision of ongoing human and economic occupation involving local people, secondary markets, entrepreneurs and adaptive management will achieve more generative, integrated and successful mine closure outcomes than regulatory planning. Research into legal, policy and capital market options to support the approach is needed.

\section{References}

Adey, EA \& Whitbread, PH 2013 'Social mine closure planning: how is it changing and why?', in M Tibbett, AB Fourie \& C Digby (eds), Proceedings of the Eighth International Conference on Mine Closure, Australian Centre for Geomechanics, Perth, pp. 431-439.

Breadmore, RE \& Lafferty, GJ 2015, 'Mine closure and first nations - social licence strategies for effective community engagement', in AB Fourie, M Tibbett, L Sawatsky \& D van Zyl (eds), Proceedings of the 10th International Conference on Mine Closure, InfoMine, pp. 753-762.

Costa, S 2015, 'Social impacts of mine closure: engaging employees and host communities in planning for closure', in AB Fourie, M Tibbett, L Sawatsky \& D van Zyl (eds), Proceedings of the 10th International Conference on Mine Closure, InfoMine, pp. 797-804.

Harvey, BE 2013, 'Social Development will not deliver social licence to operate for the extractive sector', Extractive Industries and Society, vol. 1, no. 1, pp. 7-11.

ICMM (International Council on Mining and Metals) 2011, Planning for Integrated Mine Closure Toolkit, London.

Jones, CE \& MacLean, MLA 2013, 'Reclaimed landscapes - incorporating cultural values', in M Tibbett, AB Fourie \& C Digby (eds), Proceedings of the Eighth International Conference on Mine Closure, Australian Centre for Geomechanics, Perth, pp. 441-446.

Kangwon Land Co. Ltd. 2015, Business Introduction, viewed 28 November 2015, http://kangwonland.high1.com/eng/ businessIntroduction/html.high1

Mireco 2013, Mireco Sustainability Report 2012, Mireco, Seoul, viewed 28 November 2015, http://static.globalreporting.org/ report-pdfs/2013/981b0c87aa72440b0ebb450ea7fa7728.pdf

Pearman, GI 2009, 101 things to do with a hole in the ground, Eden Project, United Kingdom.

Smith, HD \& Thompson, A 2013, 'Towards closure at Jabiluka: rehabilitation of the Boyweg-Almudj sacred site complex', in M Tibbett, AB Fourie \& C Digby (eds), Proceedings of the Eighth International Conference on Mine Closure, Australian Centre for Geomechanics, Perth, pp. 423-429.

Thomson, I 2013, 'Key issues for socially responsible mine closure: a comparative examination of corporate policies and practice', in M Tibbett, AB Fourie \& C Digby (eds), Proceedings of the Eighth International Conference on Mine Closure, Australian Centre for Geomechanics, Perth, pp. 463-472.

Van Vlaenderen, H, Guicherit, H, Hendrik, H, Watt, C, Stewart, W, Nandlal, A \& George, J 2013, 'Mine closure: merging multiple discourses', in M Tibbett, AB Fourie \& C Digby (eds), Proceedings of the Eighth International Conference on Mine Closure, Australian Centre for Geomechanics, Perth, pp. 473-482.

Veolia 2014, Woodlawn, viewed 28 November 2015, http://www.veolia.com.au/sustainable-solutions/community-development/ woodlawn-bioreactor 
